\title{
Integration of Information Assurance and Security into the IT2005 Model Curriculum
}

\author{
Melissa Jane Dark \\ Purdue University \\ 467 Knoy 401 N Grant St \\ West Lafayette, IN \\ 765-494-2254 \\ dark@purdue.edu
}

\author{
Joseph J. Ekstrom \\ Brigham Young University \\ 265 CTB \\ Provo, Utah \\ 801-422-1839 \\ Jekstrom@byu.edu
}

\author{
Barry M. Lunt \\ Brigham Young University \\ 265 CTB \\ Provo, Utah \\ 801-422-2264 \\ luntb@byu.edu
}

\begin{abstract}
In this paper we present the context of the work of the Curriculum Committee on IT2005, the IT curriculum volume described in the Overview Draft document of the Joint Task Force for Computing Curriculum 2004. We also provide a brief introduction to the history and work of the Information Assurance Education community. These two perspectives provide the foundation for the main thrust of the paper, which is a description of the Information Assurance and Security (IAS) component of the IT2005 document. Finally, we end the paper with an example of how IAS is being implemented at BYU as a "pervasive theme" that is woven throughout the curriculum and conclude with some observations about the first year's experience.
\end{abstract}

\section{Categories and Subject Descriptors}

K.3.2 [Computer and Information Science Education]

Accreditation

\section{General Terms: Management, Security}

Keywords: Information Assurance, Information Technology, CC2005, IT2005, Education, IT, IA, IAS, Pervasive Themes

\section{INTRODUCTION}

In December 2001 a meeting (CITC-1) of interested parties from fifteen four-year IT programs from the US along with representatives from IEEE, ACM, and ABET began work on the formalization of Information Technology as an accredited academic discipline. The effort has evolved into SIGITE, the ACM SIG for Information Technology Education. During this evolution three main efforts have proceeded in parallel: 1) Definition of accreditation standards for IT programs, 2) Creation of a model curriculum for four-year IT programs, and 3) Description of the characteristics that distinguish IT programs from the sister disciplines in computing.

One of the biggest challenges during the creation of the model curriculum was understanding and presenting the knowledge area

Permission to make digital or hard copies of all or part of this work for personal or classroom use is granted without fee provided that copies are not made or distributed for profit or commercial advantage and that copies bear this notice and the full citation on the first page. To copy otherwise, or republish, to post on servers or to redistribute to lists, requires prior specific permission and/or a fee.

SIGITE'05, October 20-22, 2005, Newark, New Jersey, USA.

Copyright 2005 ACM 1-59593-252-6/05/0010...\$5.00. that was originally called "security". Some of us were uncomfortable with the term because it was not broad enough to cover the range of concepts that we felt needed to be covered. We became aware of a community that had resolved many of the issues associated with the broader context we were seeking, Information Assurance. Information assurance has been defined as "a set of measures intended to protect and defend information and information systems by ensuring their availability, integrity, authentication, confidentiality, and non-repudiation. This includes providing for restoration of information systems by incorporating protection, detection, and reaction capabilities." The IA community and work done by IA educators became useful in defining requisite security knowledge for information technology education programs.

We believe that the Information Technology and the Information Assurance Education communities have much to share. At the $9^{\text {th }}$ Colloquium for Information System Security Education in Atlanta we introduced CC2005 and IT2005 to the IA Education community[1]. In the current paper we introduce the history and current state of IA education to the SIGITE community. In addition, we demonstrate how significant concepts from the Information Assurance community have been integrated into IT2005.

\subsection{CC2005 and IT2005}

In the first week of December of 2001 representatives from 15 undergraduate information technology (IT) programs from across the country gathered together near Provo, Utah, to develop a community and begin to establish academic standards for this rapidly growing discipline. This first Conference on Information Technology Curriculum (CITC-1) was also attended by representatives from two professional societies, the Association for Computing Machinery (ACM) and the Institute of Electrical and Electronics Engineers, Inc. (IEEE), and also the Accreditation Board for Engineering and Technology, Inc. (ABET). This invitational conference was the culmination of an effort begun several months earlier by five of these universities who had formed a steering committee to organize a response from existing IT programs to several initiatives to define the academic discipline of IT. The steering committee wanted to ensure that the input of existing programs played a significant role in the definition of the field.

A formal society and three main committees were formed by the attendees of CITC-1. The society was the Society for Information Technology Education (SITE); one of the committees formed was 
the executive board for SITE, composed of a president, vicepresident, secretary, treasurer, regional representatives, and an activities chairperson. The other two committees formed were the IT Curriculum Committee, including subcommittees for 4-year and 2-year programs, and the IT Accreditation Committee, also including subcommittees for 4-year and 2-year programs.

The development of IT as an academic discipline is similar to the process that computer science (CS) went through in the 70's and 80 's. In fact, looking at the placement of CS programs in academic institutions around the U.S. illustrates the debate that swirled around the discipline as its core was being defined. Some CS programs are in departments of mathematics, others are in engineering schools, and many others have become mainstay programs within newly emerging colleges of computing.

Information technology, as it is practiced at this moment in its evolution, reflects similar growing pains. IT programs exist in colleges of computing, in CS departments, in schools of technology, and in business schools. Professors of information technology possess degrees in information systems, electronics, communications, graphics arts, economics, mathematics, computer science, and other disciplines. Few to none of them have a degree in information technology.

It should be acknowledged here that IT has two substantially different interpretations, and that these should be clarified. Information Technology (IT) in its broadest sense encompasses all aspects of computing technology. IT, as an academic discipline, focuses on meeting the needs of users within an organizational and societal context through the selection, creation, application, integration and administration of computing technologies. A more detailed history of SIGITE is available in [2].

SIGITE is directly involved with the Joint Task Force for Computing Curriculum 2004 and has 2 representatives on the task force. This task force is a continuation of the effort that created CC2001 [3] the current computer science curriculum standard. CC2001 has been relabeled CS2001 and the current draft of the CC2004 Overview document [4] presents the structure being used to describe computing and its sub-disciplines (See Figure 1). The SIGITE Curriculum Committee is responsible for IT2005, the Information Technology Curriculum Volume. IT2005 was made available for comment in mid 2005.

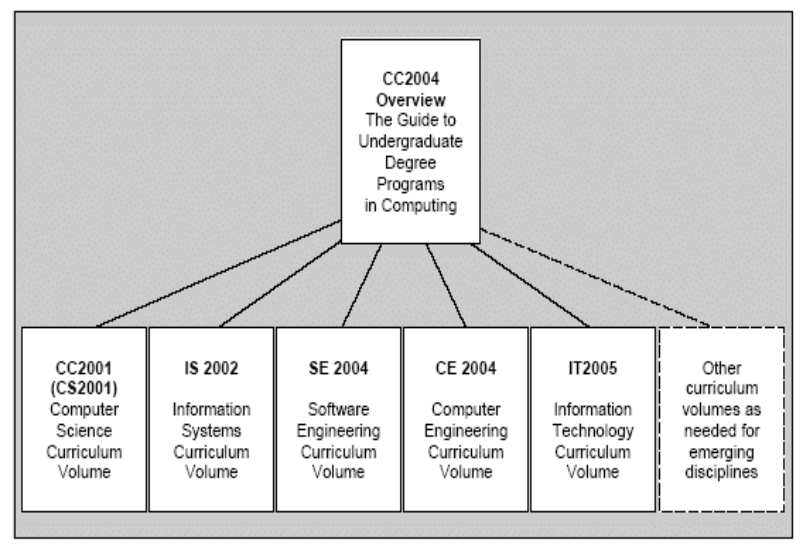

Figure 1

\subsection{Information Assurance Education}

Information assurance has been defined as "a set of measures intended to protect and defend information and information systems by ensuring their availability, integrity, authentication, confidentiality, and non-repudiation. This includes providing for restoration of information systems by incorporating protection, detection, and reaction capabilities." (National Security Agency, http://www.nsa.gov/ia/iaFAQ.cfm?MenuID=10\#1).[5]

Information assurance education, then, includes all efforts to prepare a workforce with the needed knowledge, skills, and abilities to assure our information systems, especially critical national security systems. Information assurance education has been growing in importance and activity for the past two decades. A brief look at the involved entities and history will shed light on the growth.

The National Information Assurance Education and Training Partnership (NIETP) program is a partnership among government, academia and industry focused on advancing information assurance education, training, and awareness. The NIETP was initiated in 1990 under National Security Directive 42 and has since been reauthorized several times. The NIETP serves in the capacity of national manager for information assurance education and training related to national security systems and coordinates this effort with the Committee on National Security Systems (CNSS). "The CNSS provides a forum for the discussion of policy issues, sets national policy, and promulgates direction, operational procedures, and guidance for the security of national security systems. National security systems are information systems operated by the U.S. Government, its contractors or agents that contain classified information or that:

1. involve intelligence activities;

2. involve cryptographic activities related to national security;

3. involve command and control of military forces;

4. involve equipment that is an integral part of a weapon or weapons system(s); or

5. are critical to the direct fulfillment of military or intelligence missions (not including routine administrative and business applications)." http://www.cnss.gov/history.html[6]

CNSS is responsible for the development of principles, policies, guidelines, and standards that concern systems holding or related to national security information. Education and training standards are among the many standards and guidelines that CNSS issues. The training/education standards issued to date include: a) NSTISSI $^{1} 4011$ - The National Training Standard for Information Systems Security Professionals, b) CNSSI 4012 - The National Information Assurance Training Standard for Senior Systems Managers, c) CNSSI 4013 - The National Information Assurance Training Standard for System Administrators, d) CNSSI 4014 Information Assurance Training Standard for Information Systems Security Officers, and e) NSTISSI 4015 - The National Training Standard for Systems Certifiers. CNSSI 4016 - The National

\footnotetext{
${ }^{1}$ Under Executive Order (E.O.) 13231 of October 16, 2001, Critical Infrastructure Protection in the Information Age, the President redesigned the National Security Telecommunications and Information Systems Security Committee (NSTISSC) as the Committee on National Security Systems (CNSS)
} 
Training Standard for Information Security Risk Analysts will be released soon.

The NSTISSI-CNSSI standards referenced above have been used to develop in-service training and education opportunities for enlisted and civilian employees in an effort to assure quality preparation of professionals entrusted with securing our critical information. In addition to providing a basis for in-service education and training, the NSTISSI-CNSSI standards have also been deployed to colleges and universities in an effort to also prepare qualified individuals preservice. The most significant effort to involve colleges and universities has been through the National Centers of Academic Excellence in Information Assurance Education (CAEIAE) Program. The CAEIAE program was started in 1998 by the National Security Agency (NSA) and is now jointly sponsored by the NSA and the Department of Homeland Security (DHS) in support of the President's National Strategy to Secure Cyberspace, February 2003. The purpose of the program is to recognize colleges and universities for their efforts in information assurance education and also to encourage more colleges and universities to develop courses and programs of study in information assurance. In order to be eligible to apply for CAEIAE certification, an institution must first demonstrate that it teaches the content covered in NSTISSI 4011 - The National Training Standard for Information Systems Security Professionals. Once an institution has been 4011 certified, it is eligible to apply for CAEIAE status. Criteria for becoming a CAEIAE include the following: a) evidence of partnerships in IA education, b) IA must be treated as a multidisciplinary science, c) evidence that the university encourages the practice of information assurance in its operations, d) demonstration of information assurance research, e) demonstration that the IA curriculum reaches beyond physical geographic borders, f) evidence of faculty productivity in information assurance research and scholarship, g) demonstration of state of the art information assurance resources, h) a declared concentration(s) in information assurance, i) a university recognized center in information assurance, and j) dedicated information assurance faculty (http://www.nsa.gov/ia/academia/caeCriteria.cfm?MenuID=10.1.1 .2). [7]

In 1999, there were seven institutions designated as the inaugural CAEIAE schools. The certification is good for three years at which time institutions can reapply. Annually, an additional 6-10 institutions are awarded the certification; today, there are more than 60 CAEIAE institutions. The types of institutions and programs that are applying and being certified are growing not just in number, but also in diversity. In the first round of certification, the institutions were largely research institutions and their respective programs were at the graduate level in computer science. Today, institutions are certifying courses at the undergraduate level in computer science, management information systems, and information technology. The work being done by SIGITE is important to the further expansion of information assurance education as information assurance expands beyond the development of information systems to include the entire system life cycle including deployment, operation, maintenance, a retirement of such systems.

\section{Information Assurance in IT2005}

The IT2005 volume is modeled on CS2001. It consists of 12 chapters and 2 appendices. The current draft resides at http://sigite.acm.org/activities/curriculum/[8]

- Chapter 1. Introduction

- Chapter 2. Lessons from Past Reports

- Chapter 3. Changes in the Information Technology Discipline

- Chapter 4. Principles

- Chapter 5. Overview of the IT Body of Knowledge

- Chapter 6. Overview of the Curricular Models

- Chapter 7. The Core of the Curriculum

- Chapter 8. Completing the Curriculum

- Chapter 9. Professional Practice

- Chapter 10. Characteristics of IT Graduates

- Chapter 11. Computing across the Curriculum

- Chapter 12. Institutional Challenges

- Acknowledgements

- Bibliography

- Appendix A. The IT Body of Knowledge

- $\quad$ Appendix B. IT Course Descriptions

Chapters 5 and 7 are of particular interest for this discussion. Chapter 5 is an overview of the IT body of knowledge. A summary is included as Appendix A. Chapter 7 discusses the relationship of the core topics described in the body of knowledge to IT curriculum. IAS is explicitly mentioned in three contexts:

- $\quad$ Section 7.2 as part of the IT Fundamentals Knowledge Area (KA)

- Section 7.2 as a "pervasive theme"

- Section 7.4 as a KA that integrates the IAS concepts for students ready to graduate.

IAS is the only area that is an IT Fundamental, a "pervasive theme" and also a complete KA with a recommended senior level course for integrating all of the concepts. Clearly, IT2005 presents Information Assurance and Security as a core competency required by every graduate of an IT program.

During the early analysis of IT as an academic discipline, Delphi studies were performed that ranked "Security" as a central area for IT. [1] As we studied the issues several members of the committees involved were uncomfortable with "security" as the name for the knowledge area. The name seemed too restrictive. At the annual SIGITE conference in 2003 two of the authors were introduced to the other author and the Center for Research and Education in Information Assurance and Security (Cerias) at Purdue. The BYU faculty was dissatisfied with the security component in the IT curriculum and the SIGITE curriculum committee was struggling with the Security KA for IT2005. Through flyers at the conference we became aware of the Information Assurance Education Graduate Certificate (IAEGC) program funded by the NSA. With encouragement from colleagues and the administration of the School of Technology, the primary author attended the 2004 program. The experience has had a significant impact on IT2005 and the BYU curriculum. 
We discovered that NSA had begun to use the umbrella term Information Assurance [9] to cover what we were calling security. Even though this term is defined to cover exactly what the IT community meant by security, the use of the terminology elicited a lot of blank stares. We found that explicitly adding security to the name of the knowledge area eliminated much of the confusion. We are indebted to the Center for Education and Research for Information Assurance and Security (CERIAS)[10] at Purdue whose name provided the inspiration to use IAS as a name for the knowledge area.

Once the naming issue was resolved, the SIGITE curriculum committee struggled to find a model for IAS that could

- be understood by freshman IT students

- $\quad$ provide a framework to integrate IAS concepts that are integrated into nearly all of the other KAs

- $\quad$ be rich enough to support a senior level course that ties everything together.

When A Model for Information Assurance: An Integrative Approach [11] was discovered the writing committee achieved consensus on a model. The cube (see Figure 2) provides a simple visual representation that a freshman can understand, yet the 3 dimensional structure facilitates the detailed analysis required for use in technology specific contexts, and is comprehensive enough to encompass a capstone learning experience.

\section{Information Assurance Model}

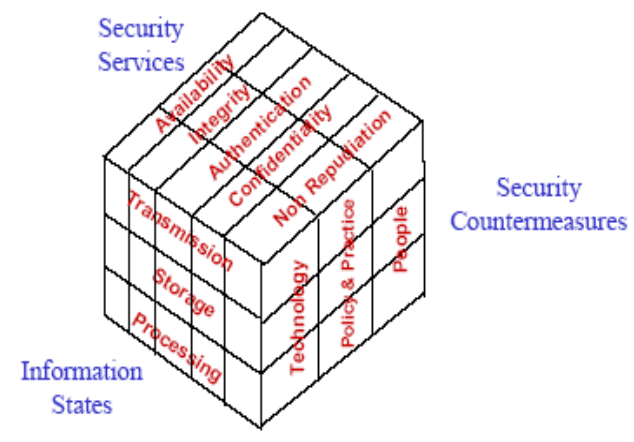

Figure 2

IT2005 uses this model to structure IAS concepts throughout the document.

\section{RECOMMENDATIONS FOR "PERVASIVE THEMES" IN IT2005}

During the deliberations of the SIGITE Curriculum Committee, several topics emerged that were considered essential, but that did not seem to belong in a single specific knowledge area or unit. These topics, referred to as pervasive themes, are:

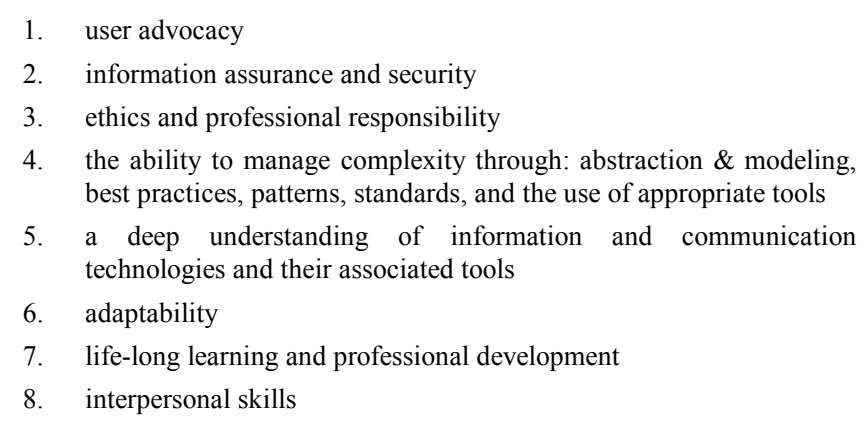

The committee states "that these topics are best addressed multiple times in multiple classes, beginning in the IT fundamentals class and woven like threads throughout the tapestry of the IT curriculum"[12].

These themes need to be made explicit in the minds of the students and the faculty. The themes touch many of the topics throughout the curriculum. Every time a new technology is announced in the media, an instructor has the opportunity to drive home the importance of "life-long learning". Every time there is a cyber-crime in the media we have the opportunity to discuss the ethical and professional ramifications. It is recommended that an IT Fundamentals course be taught early in the curriculum where all of these themes are introduced and discussed as concepts that touch everything an IT professional does.

Each of these topics deserves a full treatment; however, for the purposes of this paper we will focus on IAS, possibly the most pervasive theme. We will address one approach to achieve addressing IAS "multiple times in multiple classes" in section 6 below.

\section{THE INFORMATION ASSURANCE AND SECURITY KNOWLEDGE AREA}

In early 2003, the SIGITE curriculum committee divided into working groups around the knowledge areas defined by [3] to make an initial cut at the list of topics for each KA. A significant revision was accomplished and reviewed by the participants at the 2004 IAEGC program at Purdue in August 2004. The list of areas for the IAS KA was finalized in late 2004 at a full IT Curriculum Committee meeting. The draft of the completed IAS KA was completed in early Feb 2005 by the IAS working group, edited by the writing committee in late Feb 2005 and was presented to the full committee in April 2005.

Figure 3 is a list of the IAS KA and its areas. The basic structure and vocabulary is derived directly from work done in the IA community, specifically Maconachy, et. al.[11]. The number in parenthesis is the number of lecture hours the committee thought would be required to give an IT student minimum exposure to the unit. It should be noted that the ordering of units in all of the KAs, is first "Fundamentals", if there is one, and then the units are sorted in order of the number of core hours. This ordering should not be considered as any indication of the order the units would be covered pedagogically in an implemented curriculum. 


\section{IAS. Information Assurance and Security (23 core hours)}

IAS1. Fundamental Aspects (3)

IAS2. Security Mechanisms (countermeasures) (5)

IAS3. Operational Issues (3)

IAS4. Policy (3)

IAS5. Attacks (2)

IAS6. Security Domains (2)

IAS7. Forensics (1)

IAS8. Information States (1)

IAS9. Security Services (1)

IAS10. Threat Analysis Model (1)

IAS11. Vulnerabilities (1)

\section{Figure 3}

A summary of the IAS KA is in Appendix A, and a complete treatment is found in IT2005 [4], including topics, core learning outcomes, and example elective learning outcomes.

In reviewing this model curriculum for IAS in Information Technology, it should be remembered that the core topics and associated lecture hours are the minimum coverage that every IT student in every program should receive. We would expect that most institutions would provide additional instruction in Information Assurance and Security according to the strengths/areas of specialization in their programs of study.

\section{IT AT BRIGHAM YOUNG UNIVERSITY}

The Information Technology program at BYU began officially in Fall 2001 with a faculty consisting of:

1. Two electronics engineering technology (EET) professors who were instrumental in the evolution of the existing EET program at BYU into an IT program,

2. One electrical engineering, Ph.D. newly arrived from the aerospace industry.

3. One computer science instructor who had done part time teaching and had been part of the department for 1 year with several years in system development in health care.

4. One computer science Ph.D. with recent executive management responsibilities in network hardware and service provider businesses.

5. The former department chair of the technology education program for secondary schools joined in 2002.

6. One computer science $\mathrm{Ph}$. D. with extensive industry experience in data privacy and IT management joined in 2004.

This is obviously a diverse group of people, each of whom joined the department because they thought that the existing computing programs at BYU did not offer students preparation for the practical aspects of system delivery to customers. We are evenly divided between long-term academics and recent 'retreads' from industry. However, the academics have also each had significant industrial experience, which provided the motivation for them to accept positions in the new IT program. The BYU curriculum began as a traditional "stovepipe" approach of courses oriented around topics like networking, databases, and operating systems borrowed from CS, EET, CE and IS, and evolved to a more integrated approach starting at the introductory levels so that advanced topic oriented courses are more easily sequenced. We have also discovered that the integrative nature of IT forces a focus on the seams between technologies rather than implementation of components. This fundamental difference in focus is one of the primary differences that distinguishes IT from other computing disciplines that focus on the design and implementation of components[12] [13]. Over the last 4 years, BYU faculty has participated actively in SIGITE and attempted to share what has been learned with the emerging IT community. [14] [15] [16]

The BYU curriculum has evolved into what IT2005 calls a "core/integration first" approach [17]. Significant portions of the introductory material in operating systems, databases, web systems, networking had been moved to lower division courses by early 2004. Much of the shift occurred when the introduction to web systems was moved from the junior to the sophomore year and introductory material sufficient to understand web systems was included for networking, databases, operating system administration and OS process models. The improvements in flow and reduced redundancy have been noticeable in the upper division core courses. Appendix B graphs the current BYU course structure. In late 2004 and early 2005 we began implementing the "pervasive theme" of IAS in earnest.

\section{INTEGRATING IAS INTO THE EXISTING BYU CURRICULUM}

A senior level IAS class had been introduced into the curriculum in early 2004 and was made a requirement in 2005 . However, we recognized that simply adding a required course at the end of a student's college experience would not be adequate. SIGITE discussions had placed security in the pervasive theme category at the very beginning, though the name of the KA wasn't chosen until 2004. We were faced with the challenge of integrating the IAS fundamentals into the introductory courses, morphing the security modules in the existing classes to use the MSRW [11] framework and bringing all of the students in the program up to speed on the new framework simultaneously.

Our approach has been to prepare one hour modules on the MSRW framework that can be used in an existing course to bring students up to speed or taught in seminars as needed. We are in the process of integrating the IAS Fundamentals into our introductory courses. We successfully integrated the IAS modules into the sophomore introduction to web-based systems course, which was already introducing all of the major IT areas. The course was modified to replace a 3 week team project experience with a 2 week team oriented lab and then using the time for IAS topics. Much remains to be done, but the initial experience is positive. The faculty seems unified in their desire to implement IAS as a pervasive theme. For example, 2 lecture and 2 lab hours are now included in the computer communications course. 3 lecture hours and 3 lab hours were added to the web systems course. The IAS component of the database course was rearranged and strengthened with 1 lecture hour added. Similar adjustments have been made throughout the curriculum. 
In addition to improving the IAS component of the BYU curriculum, we have done an analysis of our coverage of the proposed IT2005 core. We have several adjustments in other parts of our curriculum. Since we evolved from an EET program, the hardware coverage was extremely strong. We are weak in the coverage of systems and database administration. We will continue to adjust our curriculum as IT matures as an academic discipline.

\section{SUMMARY}

Information Technology is maturing rapidly as an academic discipline. A public draft of the IT volume described in the Computing Curriculum 2004 Overview is ready for review. The SIGITE Curriculum Committee is soliciting feedback on the document. This paper presents a brief history of SIGITE, the ACM SIG for Information Technology Education, and a brief introduction to the Information Assurance Education community. The authors believe that collaboration between these communities can be of benefit to all of the participants and the industry at large.

SIGITE and the CC 2005 Joint Task Force solicit feedback on the documents at http://www.acm.org/education/ .

\section{ACKNOWLEDGMENTS}

The authors would like to thank the ACM Education committee for their support of the IT2005 effort, especially Russ Shackleford, without whose financial support and encouragement the document would be years away from completion. We would also like to express appreciation to the NSA for funding the IAEGC[18] program. Corey Schou's IAEGC lecture on helping students understand IAS in an hour was the genesis of the IAS approach in IT2005. The BYU authors would like to express appreciation to our colleagues and the administration of the School of Technology at Brigham Young University, who covered our classes and found the funding for the time and travel our participation in the SIGITE curriculum committee required.

\section{REFERENCES}

[1] Ekstrom, Joseph J., Lunt, Barry M., Integration of Information Assurance and Security into IT2005, $9^{\text {th }}$ Colloquium for Information Systems Security Education, June 6-9, 2005, Atlanta, Georgia.

[2] Lunt, Barry M.; Ekstrom, Joseph J.; Lawson, Edith A.; Kamali, Reza; Miller, Jacob; Gorka, Sandra; Reichgelt, Han; "Defining the IT Curriculum: The Results of the Last 21/2 Years"; World Engineer's Convention 2004, Shanghai, China; Nov 2-6, 2004

[3] Joint Task Force for Computing Curricula (2001), Computing Curricula 2001, Computer Science Volume, December 15, 2001, Copyright 2001, ACM/IEEE
[4] ]Joint Task Force for Computing Curricula (2004), Computing Curricula 2004: Overview Document, http://www.acm.org/education/Overview_Draft_11-2204.pdf retrieved Mar. 2, 2005.

[5] http://www.nsa.gov/ia/iaFAQ.cfm?MenuID=10\#1

[6] http://www.cnss.gov/history.html

[7]

http://www.nsa.gov/ia/academia/caeCriteria.cfm?MenuID=1 0.1.1.2

[8] SIGITE Curriculum Committee (2005), Computing Curriculum 2005, IT Volume, http://sigite.acm.org/activities/curriculum/

[9] NSA web site, Information Assurance Division; http://www.nsa.gov/ia/ verified Mar, 4, 2005.

[10] Cerias web site, http://cerias.purdue.edu/; verified Mar 4, 2005

[11] Machonachy, W. Victor; Schou, Corey D.; Ragsdale, Daniel; Welch , Don; "A model for Information Assurance: An Integrated Approach", Proceedings of the 2001 IEEE Workshop on Information Assurance and Security, United States Military Academy, West Point, NY, 5-6 June 2001.

[12] Ekstrom, Joseph, Renshaw, Stephen, Curriculum and Issues in a First Course of Computer Networking for Four-year Information Technology Programs, ASEE 2002 Session 2793

[13] Ekstrom, Joseph, Renshaw, Stephen, A Project-Based Introductory Curriculum in Networking, WEB and Database Systems for 4-year Information Technology Programs, CITC 3 Rochester NY, September, 2002

[14] Ekstrom, Joseph, Renshaw, Stephen, Database Curriculum Issues for Four-year IT Programs, CIEC 2003, Tucson, AZ, January, 2003.

[15] Ekstrom, Joseph; Lunt, Barry; Education at the Seams: Preparing Students to Stitch Systems Together; Curriculum and Issues for 4-Year IT Programs, CITC IV Purdue University, West Lafayette, Indiana, October 2003.

[16] Ekstrom, Joseph; Lunt, Barry M; Helps, C. Richard; Education at the Seams: Preliminary Evaluation of Teaching Integration as a Key to Education in Information Technology; ASEE 2004, Salt Lake City, Utah, June 2004.

[17] Section 6.3 of ref [4].

[18] IAEGC, Information Assurance Education Graduate Certificate, http://www.cerias.purdue.edu/iae Validated April 13, 2005. 


\section{Appendix A \\ From IT2005 Mar 2005 Draft}

\section{$\underline{\text { The Information Technology Body of Knowledge }}$}

ITF. Information Technology Fundamentals (33 core)

ITF1. Pervasive Themes in IT (17)

ITF2. Organizational Issues (6)

ITF3. History of IT (3)

ITF4. IT and Its Related and Informing Disciplines (3)

ITF5. Application Domains (2)

ITF6. Applications of Math and Statistics to IT (2)

HCI. Human Computer Interaction (20 core hours)

HCI1. Human Factors (6)

HCI2. HCI Aspects of Application Domains (3)

HCI3. Human-Centered Evaluation (3)

HCI4. Developing Effective Interfaces (3)

HCI5. Accessibility (2)

HCI6. Emerging Technologies (2)

HCI7. Human-Centered Software (1)

IAS. Information Assurance and Security (23 core)

IAS1. Fundamental Aspects (3)

IAS2. Security Mechanisms (Countermeasures) (5)

IAS3. Operational Issues (3)

IAS4. Policy (3)

IAS5. Attacks (2)

IAS6. Security Domains (2)

IAS7. Forensics (1)

IAS8. Information States (1)

IAS9. Security Services (1)

IAS10. Threat Analysis Model (1)

IAS11. Vulnerabilities (1)

IM. Information Management (34 core hours)

IM1. IM Concepts and Fundamentals (8)

IM2. Database Query Languages (9)

IM3. Data Organization Architecture (7)

IM4. Data Modeling (6)

IM5. Managing the Database Environment (3)

IM6. Special-Purpose Databases (1)

IPT. Integrative Programming \& Technologies (23 core)

IPT1. Intersystems Communications (5)

IPT2. Data Mapping and Exchange (4)

IPT3. Integrative Coding (4)

IPT4. Scripting Techniques (4)

IPT5. Software Security Practices (4)

IPT6. Miscellaneous Issues (1)

IPT7. Overview of programming languages (1)

NET. Networking (20 core hours)

NET1. Foundations of Networking (3).

NET2. Routing and Switching (8)

NET3. Physical Layer (6)

NET4. Security (2)

NET5. Application Areas (1)

NET6. Network Management
PF. Programming Fundamentals (38 core hours)

PF1. Fundamental Data Structures (10)

PF2. Fundamental Programming Constructs (9)

PF3. Object-Oriented Programming (9)

PF4. Algorithms and Problem-Solving (6)

PF5. Event-Driven Programming (3)

PF6. Recursion (1)

PT. Platform Technologies (14 core hours)

PT1. Operating Systems (10)

PT2. Architecture and Organization (3)

PT3. Computer Infrastructure (1)

PT4. Enterprise Deployment Software

PT5. Firmware

PT6. Hardware

SA. System Administration and Maintenance (11 core hours)

SA1. Operating Systems (4)

SA2. Applications (3)

SA3. Administrative Activities (2)

SA4. Administrative Domains (2)

SIA. System Integration and Architecture (21 core hours)

SIA1. Requirements (6)

SIA2. Acquisition/Sourcing (4)

SIA3. Integration (3)

SIA4. Project Management (3)

SIA5. Testing and QA (3)

SIA6. Organizational Context (1)

SIA7. Architecture (1)

SP. Social and Professional Issues (23 core hours)

SP1. Technical Writing for IT (5)

SP2. History of Computing (3)

SP3. Social Context of Computing (3)

SP4. Teamwork Concepts and Issues (3)

SP5. Intellectual Properties (2)

SP6. Legal Issues in Computing (2)

SP7. Organizational Context (2)

SP8. Professional and Ethical Issues and Responsibilities (2)

SP9. Privacy and Civil Liberties (1)

WS. Web Systems and Technologies ( 21 core hours)

WS1. Web Technologies (10)

WS2. Information Architecture (4)

WS3. Digital Media (3)

WS4. Web Development (3)

WS5. Vulnerabilities (1)

WS6. Social Software

Total Hours: 281

Notes:

1. Order of Knowledge Areas: Fundamentals first, then ordered alphabetically.

2. Order of Units under each Knowledge Area: Fundamentals first (if present),

then ordered by number of core hours. 


\section{Appendix B}

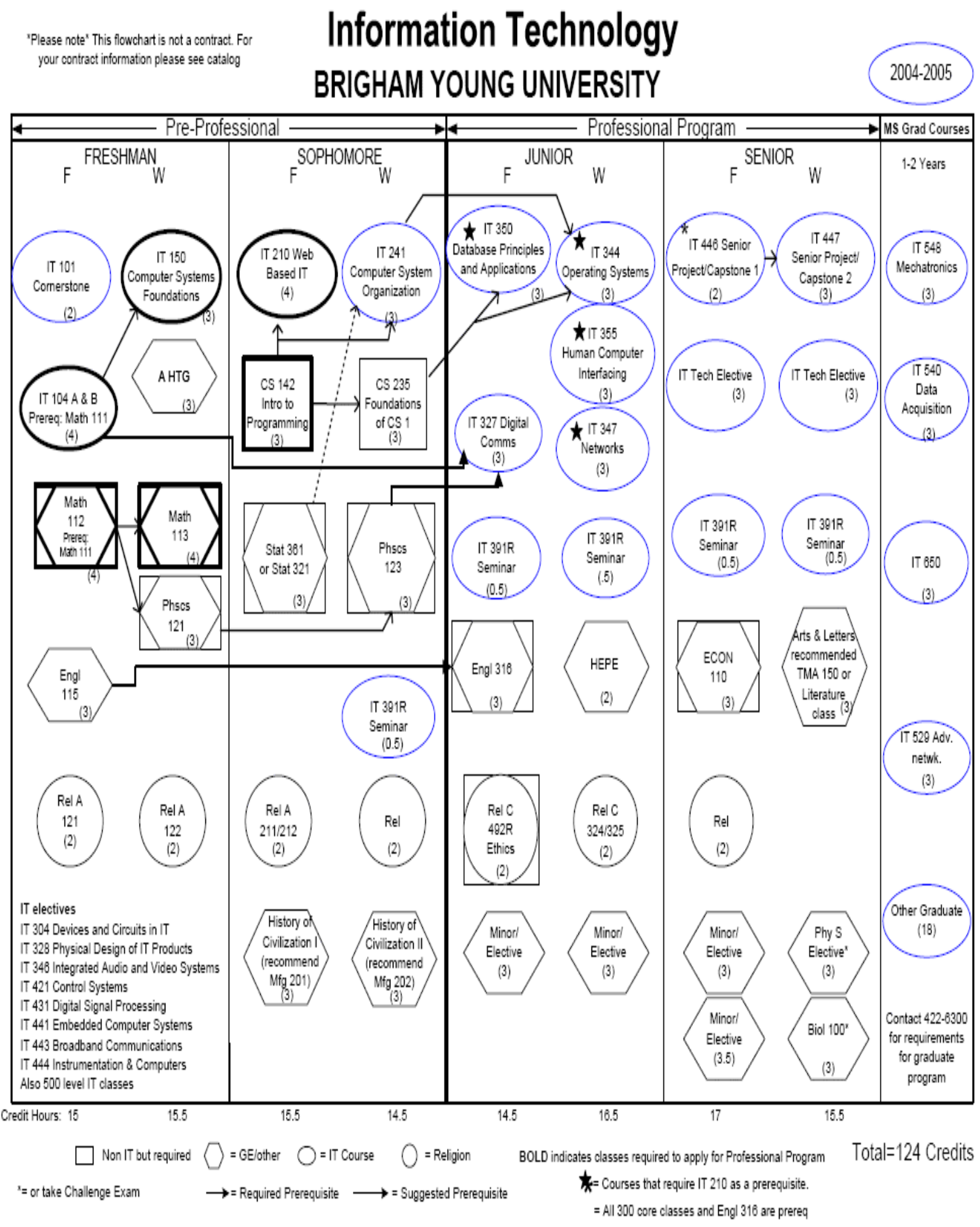

